concludes with a very adequate list of references.

This is clearly a book for the specialist, yet there are parts of each article from which the tyro can learn and profit. But, as so often happens today, the price will probably restrict purchases to libraries and to committed research groups. K. J. STANDLEY

\section{Research on Whales}

The Sperm Whale. By A. A. Berzin. Translated from Russian. Pp. v+394. (Israel Program for Scientific Information: Jerusalem; Wiley: Chichester, March 1973.) £13.15.

THE sperm whale is the most numerous of the great whales. It contributes about $60 \%$ to the world catch of large whales, and nearly half are taken by the USSR. It is also biologically fascinating because of its adaptations to the marine environment. This dual interest led Dr Berzin to assemble his monograph of all the data available on the sperm whale up to 1968 . The Soviet whaling fleets in the North Pacific and Antarctic and cruises by research vessels have provided much information which is not widely known to non-Russian scientists, so this critical review of published work and the author's original material is a competent and most welcome survey.

Preferring the specific name Physeter macrocephalus L. (1785), Berzin recognizes northern and southern hemisphere sub-species differing slightly in morphometry but not in colour. He covers the osteology of the sperm whale, its digestive, respiratory and urinogenital systems, and with V. M. Malyshev, gives the first full account of the musculature. Recent work on the brain is outlined, and the structure and possible functions of the skin are considered, including the questions of laminar flow and thermoregulation. The curiously formed head of the sperm whale has long intrigued researchers, and recent evidence suggests functions of the nasal passages and spermaceti organ connected with sound production. It is encouraging to find that Berzin states the theories but also expresses reservations where necessary on this and other unproven aspects of the whale's biology.

Research on whales has tended to proceed in parallel in the Soviet Union and outside in recent years, perhaps because of the language problem. This is particularly apparent in the discussion of reproduction and age determination. For example, the author suggests that ovulation in the females is induced, foetal growth is not constant, lactation lasts only one year, and he gives important evidence for believing that two growth layers are formed in the tooth dentine each year. Opinion elsewhere differs on these subjects, partly because the Soviet results published as long ago as 1961 have not been widely considercd. It is good to have a truly critical review of Soviet research available now, and this may help to avoid a repetition of the situation where the slow maturation of the sperm whale testis was described by Berzin in 1963 but recognized independently by other workers some five years later.

Other subjects dealt with are behaviour, and diseases and parasites, including a thorough survey of the helminth fauna by S. L. Delyamure and A. S. Skryabin. Food species, mainly cephalopods, may influence the distribution of sperm whales, and reference is made to the large body of relevant data accumulated in the USSR. There is also an outline of sperm whale catches world-wide, with a useful account of Soviet whaling methods and products.

Our knowledge of sperm whale biology, and reproduction in particular, has advanced since the last of the extensive references quoted was published, but otherwise this excellent translation gives a comprehensive picture of an important international resource.

RAY Gambell

\section{Light-Scattering}

Light Scattering from Polymer Solutions. Edited by M. B. Huglin. Pp. xviii +885 . (Academic: New York and London, August 1972.) £14.50; $\$ 45$.

THE method of light-scattering has been applied to physical chemistry of macromolecules in solution owing to the works of P. Debye in 1944 and has seen a successful development in the field of the polymers, synthetic as well as biological. From this time the abundance of literature on this subject has shown the considerable interest of the method for the study of polymer solutions.

There exist a number of reviews giving the main outlines of the theory and the various aspects of this method. A few basic papers more specialized and already published in different journals have been reprinted in one volume in 1964. But the progress in the research of polymers makes necessary a more detailed and modern review on the information obtainable by this method. Consequently the publication of a treatise entirely devoted to scattered light became indispensable. This important book fulfils this purpose. The wish of the editor is "to bridge the gap between the standard book and the papers of an extreme specialization". This new treatise on lightscattering is made up of eighteen chapters; each one, written by an expert, is self contained without reference to each other.

The topics have been selected by the editor himself. But no chapter is devoted to fundamental bases of the method, except one dealing with "large particle scattering function" $\mathbf{P}(\theta)$ which is known to yield important information on the molecular geometry. The essentials of theory are presented, more or less briefly, however, by most of the authors as an introduction to their own subject.

In the beginning of the book, five chapters concern the technology. The first one is devoted to the very important problem of clarifying the solutions. In another chapter, the various apparatuses are described, but, unfortunately, the references being no later than 1966, recent improvements such as the use of laser as light source are hardly mentioned. An important part (150 pages) is reserved for the determination of refractive index increments, which shows its importance; the tabulated data will be very useful for the experimenter.

Among the following chapters treating various problems of polymer solutions, some concern both the synthetic and biological ones. For example, chapter 9 deals with the problems of aggregation or multimerization, chapter 15 with the interactions between polymers and mixed-solvent and chapter 16 with the solutions of polyelectrolytes. But most of them are devoted to synthetic polymers, stereoregular and copolymers. It is worth noting particularly some topics which are untreated elsewhere, such as the influence of various external factors, pressure and temperature; or the effect of electric fields owing to which, beside the standard data, information on the dipolar moment, relaxation time and molecular flexibility is obtainable. The last chapter deals with the early development of the turbidimetric titration, very useful in determining the molecular weight distribution.

Although this book is devoted to "polymers" taken in the broadest sense, and so including biopolymers, the space given to biological topics, around fifty pages, permits only an incomplete view of the possibilities of the method in this field.

The rapid survey of this important volume emphasizes the wealth of information brought by the light-scattering method. But the detailed development of one subject in each chapter and the specialization of each one will make difficult the utilization of the book by anyone encountering the method for the first time. Rather it is suited to polymer scientists, already experienced researchers, for whom it will be an invaluable tool. $\quad J$. TONNELAT

S. Guinand 